\title{
Children's body mass index, participation in school meals, and observed energy intake at school meals
}

\author{
Suzanne Domel Baxter ${ }^{1 *}$, James W Hardin², Caroline H Guinn', Julie A Royer ${ }^{1}$, Alyssa J Mackelprang ${ }^{1}$, \\ Christina M Devlin ${ }^{1}$
}

\begin{abstract}
Background: Data from a dietary-reporting validation study with fourth-grade children were analyzed to investigate a possible relationship of body mass index (BMI) with daily participation in school meals and observed energy intake at school meals, and whether the relationships differed by breakfast location (classroom; cafeteria).

Methods: Data were collected in 17, 17, and 8 schools during three school years. For the three years, six, six, and seven of the schools had breakfast in the classroom; all other schools had breakfast in the cafeteria. Information about 180 days of school breakfast and school lunch participation during fourth grade for each of 1,571 children (90\% Black; $53 \%$ girls) was available in electronic administrative records from the school district. Children were weighed and measured, and BMI was calculated. Each of a subset of 465 children (95\% Black; 49\% girls) was observed eating school breakfast and school lunch on the same day. Mixed-effects regression was conducted with $\mathrm{BMI}$ as the dependent variable and school as the random effect; independent variables were breakfast participation, lunch participation, combined participation (breakfast and lunch on the same day), average observed energy intake for breakfast, average observed energy intake for lunch, sex, age, breakfast location, and school year. Analyses were repeated for BMI category (underweight/healthy weight; overweight; obese; severely obese) using pooled ordered logistic regression models that excluded sex and age.
\end{abstract}

Results: Breakfast participation, lunch participation, and combined participation were not significantly associated with $\mathrm{BMI}$ or $\mathrm{BMI}$ category irrespective of whether the model included observed energy intake at school meals. Observed energy intake at school meals was significantly and positively associated with BMI and BMI category. For the total sample and subset, breakfast location was significantly associated with BMI; average BMI was larger for children with breakfast in the classroom than in the cafeteria. Significantly more kilocalories were observed eaten at breakfast in the classroom than in the cafeteria.

Conclusions: For fourth-grade children, results provide evidence of a positive relationship between BMI and observed energy intake at school meals, and between BMI and school breakfast in the classroom; however, BMI and participation in school meals were not significantly associated.

\section{Background}

It is well known that the incidence of obesity has increased dramatically over the last several decades among children in the United States [1,2] and around the world [3]. This is of concern because overweight children are at increased risk for morbidity and mortality later in life [4].

\footnotetext{
* Correspondence: sbaxter@mailbox.sc.edu

${ }^{1}$ Institute for Families in Society, University of South Carolina, 1600 Hampton Street, Suite 507, Columbia, SC 29208 USA
}

The School Breakfast Program (SBP) and the National School Lunch Program (NSLP) are two food assistance programs administered by the United States Department of Agriculture. Millions of children participate in the SBP and NSLP each school day [5]. Children from families with incomes $\leq 130 \%$ of the poverty level are eligible for free meals, and children from families with incomes between $130 \%$ and $185 \%$ of the poverty level are eligible for reduced-price meals [6].

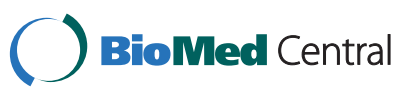

C 2010 Baxter et al; licensee BioMed Central Ltd. This is an Open Access article distributed under the terms of the Creative Commons Attribution License (http://creativecommons.org/licenses/by/2.0), which permits unrestricted use, distribution, and reproduction in any medium, provided the original work is properly cited. 
There is growing concern about whether participation in school meal programs contributes to obesity [7-9]. In a review of eating patterns and obesity, Nicklas and colleagues [10] commented that although the SBP and NSLP have had a major, generally positive impact on children's nutritional status, "the introduction of school lunch and later school breakfast has likely contributed to obesity in low-socioeconomic-status children." An Expert Panel was convened in March, 2004, by the United States Department of Agriculture to identify evidence about whether participation in food assistance programs contributes to obesity [9]. The Panel concluded that "the sparse research that has been published provides no consistent evidence of association" between participation in either the SBP or the NSLP and overweight or obesity [9].

To our knowledge, two feeding trials have investigated a relationship between participation in school meal programs and obesity. Paige [11] conducted a one-year lunch program at four elementary schools; results failed to indicate significant differences in mean increases in weight or height for fed and non-fed lunch groups after one school year. Lieberman and colleagues [12] offered free breakfast at a test elementary school but not at a control school; repeat anthropometric measurements at the test school after five months of free breakfast revealed no significant shift from initial measurements for any age or sex group.

We are aware of six non-feeding studies that have investigated a relationship between participation in school meal programs and obesity. Anthropometric results from the National Evaluation of School Nutrition Programs indicated that SBP participation was not related to height and only weakly and positively related to weight and triceps fatfold; also, NSLP participation was not related to height but was weakly and positively related to weight, which was at least partly due to an increase in triceps fatfold [13]. Wolfe and colleagues [14] found that elementary school children who tended to be fatter ate school lunch. Melnik and colleagues [15] found that overweight among elementary school children was not associated with NSLP participation. Jones and colleagues [16] found that for food-insecure children, SBP and NSLP participation was inversely associated with risk of overweight; however, for food-secure children, there was no difference in the risk of overweight by program participation. Hofferth and Curtain [17] commented that SBP and NSLP participation "may be associated with a higher chance of being overweight... children who ate a school lunch had a significantly higher BMI and a greater chance of being overweight than those who did not, and those who ate a lunch and breakfast also had a significantly higher BMI and chance of being overweight." For the third School Nutrition Dietary Assessment Study, children reported the number of times per week (zero to five) that they a) "usually eat a school breakfast" and b) "usually eat a school lunch"; although results showed no relationship between participation in the NSLP and body mass index (BMI) percentile, a negative relationship was found between participation in the SBP and BMI percentile [18].

In previous research concerning a possible relationship between childhood obesity and SBP and NSLP participation, two methodological limitations are evident. First, information about SBP and NSLP participation has relied on parental yes/no responses, or children's reports about the past few days or usual times per week. Such proxy- and self-reports are prone to error [19]. Second, information about children's intake at school meals has relied on parental and/or children's reports. However, results from validation studies indicate that parents have difficulty accurately reporting their children's intake [20-22] and that children's dietary reporting errors can be substantial [23-26]. To our knowledge, no previous research concerning a possible relationship between childhood obesity and SBP and NSLP participation has utilized daily SBP and NSLP participation, or observed intake at school meals.

When investigating a possible relationship between childhood obesity and SBP and NSLP participation, it may be important to consider the location of school breakfast. The School Breakfast Program Pilot Project [27] studied the impact of universal-free school breakfast on SBP participation and other measures. Results indicated that SBP participation was significantly higher for breakfast in the classroom (66\%) than in the cafeteria (28\%) [27]. Also, two or more breakfasts (at home and at school) on a given day were reported as eaten for a larger share of children with breakfast in the classroom than children without breakfast in the classroom, and higher intakes of energy at breakfast (but not over 24 hours) were reported for children with breakfast in the classroom than children without breakfast in the classroom [27]. (For children without breakfast in the classroom, the school cafeteria was the primary location for school breakfast.) No significant differences were found in children's BMI percentile between schools with universal-free school breakfast and schools with regular SBP (i.e., without universal-free school breakfast) [28]. However, daily SBP participation was not investigated, and children's energy intake was not observed but instead was reported by children and/or their parents.

For this article, data collected during three school years for a dietary-reporting validation study with fourth-grade children [29] were analyzed to address three research questions (RQ): 
RQ1

What is the relationship between children's BMI and daily school meal participation during the fourth-grade school year? Does this differ for breakfast and lunch participation separately versus combined, by sex, by age (in months), by breakfast location (cafeteria; classroom), and by school year?

\section{RQ2}

For a subset of fourth-grade children observed eating school meals, what is the relationship between BMI and observed energy intake at school meals? Does this differ for breakfast and lunch separately versus combined, by sex, by age, by breakfast location, and by school year?

\section{RQ3}

For a subset of fourth-grade children observed eating school meals, what is the effect on RQ1 when observed energy intake at school meals is included in the analyses?

\section{Methods}

The institutional review board at the University of South Carolina approved the project. Written parental consent and child assent were obtained. Data collection methods for the dietary-reporting validation study have been described in detail elsewhere [29]; thus, only a summary is provided here.

Data were collected in one district during three school years. During the 2004-05 school year, 17 schools participated. During the 2005-06 school year, 16 of the same schools participated along with an additional school, for a total of 17 schools. During the 2006-07 school year (when data collection needs were less), eight schools participated that had each participated in both of the first two school years. Breakfast location was not manipulated for the dietary-reporting validation study, but was determined by each school principal and was unchanged during a given school year. For the three respective school years, six, six, and seven schools had breakfast in the classroom; all other schools had breakfast in the cafeteria. Across the three school years of data collection, only one school changed its breakfast location; that school had breakfast in the cafeteria for the first two school years, and breakfast in the classroom for the third school year. The district had implemented offer-vs-serve foodservice, so children could refuse some meal items [30]. For the respective three school years, of the 933, 959, and 499 fourth-grade children invited to participate, $687(74 \%), 733(76 \%)$, and 360 (72\%) agreed, for an overall total of 1,780 children in the study.

\section{Participation in school meals}

Information about 180 possible days of school breakfast and school lunch participation during children's fourth- grade school year was obtained from electronic administrative records provided by the school district. This information was available for 1,571 (90\% Black; 53\% girls) of the 1,780 fourth-grade children in the study. For this article, breakfast participation was defined as the number of days on which a child participated in school breakfast during his or her fourth-grade school year. Lunch participation was defined as the number of days on which a child participated in school lunch during his or her fourth-grade school year. Combined participation was defined as the number of days on which a child participated in both school breakfast and school lunch during his or her fourth-grade school year.

\section{Weight/height measurements and age}

Research staff followed a written protocol and standardized procedures $[31,32]$ to weigh and measure children in the morning (after school breakfast but before school lunch) in the spring of their fourth-grade school year using digital scales and portable stadiometers. Intermeasurer reliability was assessed daily for pairs of research staff on measurements from a random $10 \%$ sample of children. Intraclass correlation reliability was $>0.99$ for weight and for height for each of the three school years. Each child's age was calculated by subtracting his or her date of birth (obtained from school records) from the date of measurement. Each child's BMI percentile was determined based on age/sex BMI charts $[33,34]$. Each child was assigned to a BMI category based on the recommendations of the Expert Committee for the Prevention, Assessment, and Treatment of Child and Adolescent Overweight and Obesity [35]. These BMI categories consisted of underweight $\left(<5^{\text {th }}\right.$ percentile), healthy weight $\left(\geq 5^{\text {th }}\right.$ to $<85^{\text {th }}$ percentiles), overweight $\left(\geq 85^{\text {th }}\right.$ to $<95^{\text {th }}$ percentiles), obese $\left(\geq 95^{\text {th }}\right.$ to $<99^{\text {th }}$ percentiles), and severely obese $\left(\geq 99^{\text {th }}\right.$ percentile).

\section{Observed intake at school meals}

Each of a subset of 465 fourth-grade children (95\% Black; $49 \%$ girls) was observed eating school breakfast and school lunch on the same day during data collection. Of the 465 children, both school meals were observed eaten on one day for 381 children, on two days for 73 children, on three days for 10 children, and on four days for 1 child, for a total of 561 days of observed school meal intake across the 465 children. For observations of school meals, researchers observed one to three children simultaneously during regular meal periods with children seated according to their school's typical arrangement. Entire meal periods were observed so that food trades (items received and/or given away) could be noted. Researchers used paper forms to record items and amounts eaten in servings of standardized school meal portions. Interobserver 
reliability [36], which was assessed weekly, was acceptable [29].

Amounts eaten of each serving were recorded as none, taste, little bit, half, most, all, or as the actual number of servings if more than one serving was observed eaten. Qualitative labels used to record observed information were assigned numeric values as none $=0.0$, taste $=0.1$, little bit $=0.25$, half $=0.5$, most $=0.75$, all $=1.0$, or as the actual number of servings if more than one serving was observed eaten. Quantified observed servings were multiplied by per-serving energy values (in kilocalories) of standardized school meal portions. These energy values were obtained primarily from the Nutrition Data System for Research (Nutrition Coordinating Center, University of Minnesota, Minneapolis, MN); however, sometimes the school district's nutrition program provided this information. For each observed meal, the values for energy intake were summed across items eaten. For each child with multiple days of observations, average observed energy intakes for breakfast and for lunch were calculated.

\section{Analyses for RQ1}

Mixed-effects regression was conducted with BMI as the dependent variable and school as the random effect. The independent variables were breakfast participation, lunch participation, combined participation, sex, age (in months), breakfast location (classroom; cafeteria), and school year. The sample for RQ1 was comprised of 1,571 children.

\section{Analyses for RQ2}

Mixed-effects regression was conducted with BMI as the dependent variable and school as the random effect. The independent variables were average observed energy intake for breakfast (in units of 100 kilocalories), average observed energy intake for lunch (in units of 100 kilocalories), sex, age, breakfast location, and school year. The sample for RQ2 was comprised of 465 children.

\section{Analyses for RQ3}

Mixed-effects regression was conducted with BMI as the dependent variable and school as the random effect. The independent variables were breakfast participation, lunch participation, combined participation, average observed energy intake for breakfast (in units of 100 kilocalories), average observed energy intake for lunch (in units of 100 kilocalories), sex, age, breakfast location, and school year. The sample for RQ3 was comprised of 465 children.

\section{Analyses for all three RQs}

In the analyses just described for each RQ, BMI was used instead of BMI percentile because numerous BMI percentile values were near the upper bound. For each of the three RQs, analyses were repeated for BMI category using pooled ordered logistic regression models; the modified sandwich variance estimator [37] adjusted standard errors for multiple observations for schools. Because BMI percentiles are based on age and sex, those measures were not included as covariates in models for BMI category. Instead of using five BMI categories for these analyses, four BMI categories were used; the very few $(20$ of 1,571$)$ children in the underweight $\left(<5^{\text {th }}\right.$ percentile) BMI category were included in the healthy weight $\left(\geq 5^{\text {th }}\right.$ to $<85^{\text {th }}$ percentiles $)$ BMI category.

\section{Post-hoc analyses}

Post-hoc two sample $t$-tests investigated differences in observed energy intake for breakfast and for lunch by breakfast location. Additional post-hoc two sample $t$-tests investigated differences in observed energy intake for breakfast and for lunch by sex. The sample for posthoc analyses was comprised of 465 children.

\section{Results}

Table 1 shows the number and percent of children by BMI category and school year. This information is shown for the 1,571 children for whom participation information was available, as well as for the subset of 465 children for whom observed intake at school meals was available.

Table 2 provides means and standard deviations for the number of days of breakfast participation, lunch participation, and combined participation, by BMI category for all 1,571 children, and for the subset of 465 observed children.

Children were in the fourth grade and had a mean age of 122.88 months. However, age ranged from 90 to 149 months.

\section{RQ1}

For analysis of BMI, sex was significant $(\mathrm{p}<0.001$; coefficient for boys $=-0.94$ ); average BMI was $0.94 \mathrm{~kg} / \mathrm{m}^{2}$ smaller for boys (20.56) than girls (21.44). For the healthy weight, overweight, obese, and severely obese BMI categories, $51 \%, 43 \%, 44 \%$, and $45 \%$ were boys, respectively.

For analysis of BMI, age was significant $(\mathrm{p}=0.006$; coefficient $=0.06$ ); BMI increased by $0.06 \mathrm{~kg} / \mathrm{m}^{2}$ as age increased by one month.

For analysis of BMI, breakfast location was significant $(\mathrm{p}=0.012$; coefficient for classroom $=0.88)$; average BMI was larger for children with breakfast in the classroom (21.50) than in the cafeteria (20.54). However, for analysis of BMI category, breakfast location was not significant $(\mathrm{p}=0.054$; odds ratio for classroom $=1.31)$; for 
Table 1 Information about children by BMI category and school year for the total sample and subset ${ }^{\mathrm{a}}$

\begin{tabular}{|c|c|c|c|c|c|c|}
\hline \multirow[b]{3}{*}{ BMI category } & \multicolumn{2}{|c|}{ 2004-05 school year } & \multicolumn{2}{|c|}{ 2005-06 school year } & \multicolumn{2}{|c|}{ 2006-07 school year } \\
\hline & $\begin{array}{c}\text { All children } \\
n=616\end{array}$ & $\begin{array}{c}\text { Subset } \\
\mathrm{n}=187\end{array}$ & $\begin{array}{c}\text { All children } \\
\mathrm{n}=646\end{array}$ & $\begin{array}{c}\text { Subset } \\
n=213\end{array}$ & $\begin{array}{c}\text { All children } \\
\mathrm{n}=309\end{array}$ & $\begin{array}{l}\text { Subset } \\
n=65\end{array}$ \\
\hline & \multicolumn{6}{|c|}{ 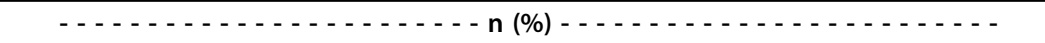 } \\
\hline Underweight \& healthy weight $\left(<85^{\text {th }}\right.$ percentile) & $322(52 \%)$ & $103(55 \%)$ & $347(54 \%)$ & $102(48 \%)$ & $142(46 \%)$ & $27(42 \%)$ \\
\hline Overweight ( $\geq 85^{\text {th }}$ to $<95^{\text {th }}$ percentiles) & $116(19 \%)$ & $29(16 \%)$ & $123(19 \%)$ & $44(21 \%)$ & $56(18 \%)$ & $14(22 \%)$ \\
\hline Obese ( $\geq 95^{\text {th }}$ to $<99^{\text {th }}$ percentiles) & $139(23 \%)$ & $41(22 \%)$ & $112(17 \%)$ & $43(20 \%)$ & $70(23 \%)$ & $16(25 \%)$ \\
\hline Severely obese ( $\geq 99^{\text {th }}$ percentile) & $39(6 \%)$ & $14(8 \%)$ & 64 (10\%) & 24 (11\%) & 41 (13\%) & $8(12 \%)$ \\
\hline
\end{tabular}

${ }^{a}$ Each child in the subset was observed eating school breakfast and school lunch (with both meals observed on the same day).

Table 2 School meal participation (in days) by BMI category for the total sample and subset ${ }^{\mathrm{a}}$

\begin{tabular}{|c|c|c|c|c|c|c|c|c|}
\hline \multirow[b]{3}{*}{ Participation } & \multicolumn{2}{|c|}{$\begin{array}{c}\text { Underweight } \& \text { healthy } \\
\text { weight } \\
\left(<85^{\text {th }} \text { percentile }\right)\end{array}$} & \multicolumn{2}{|c|}{$\begin{array}{c}\text { Overweight } \\
\left(\geq 85^{\text {th }} \text { to }<95^{\text {th }} \text { percentiles }\right)\end{array}$} & \multicolumn{2}{|c|}{$\begin{array}{c}\text { Obese } \\
\left(\geq 95^{\text {th }} \text { to }<99^{\text {th }} \text { percentiles }\right)\end{array}$} & \multicolumn{2}{|c|}{$\begin{array}{c}\text { Severely obese } \\
\left(\geq 99^{\text {th }} \text { percentile) }\right.\end{array}$} \\
\hline & $\begin{array}{l}\text { All children } \\
\mathrm{n}=811\end{array}$ & $\begin{array}{c}\text { Subset } \\
\mathrm{n}=232\end{array}$ & $\begin{array}{c}\text { All children } \\
\mathrm{n}=295\end{array}$ & $\begin{array}{l}\text { Subset } \\
\mathrm{n}=\mathbf{8 7}\end{array}$ & $\begin{array}{c}\text { All children } \\
\mathrm{n}=321\end{array}$ & $\begin{array}{c}\text { Subset } \\
n=100\end{array}$ & $\begin{array}{l}\text { All children } \\
n=144\end{array}$ & $\begin{array}{l}\text { Subset } \\
n=46\end{array}$ \\
\hline & \multicolumn{8}{|c|}{ - - - - - - - - - - - - - - - - - mean (standard deviation) - - - - - - - - - - - - - - - - - - - - - - - - } \\
\hline Breakfast $^{\mathrm{b}}$ & $104(58)$ & $141(27)$ & $104(57)$ & $141(25)$ & $106(58)$ & $142(25)$ & $107(55)$ & $140(24)$ \\
\hline Lunch $^{\mathrm{C}}$ & $156(28)$ & $162(16)$ & $155(32)$ & $163(11)$ & $156(29)$ & $161(14)$ & $157(25)$ & $163(10)$ \\
\hline Combined $^{d}$ & $98(56)$ & $133(26)$ & $97(55)$ & $133(25)$ & 99 (55) & $133(26)$ & $100(53)$ & $133(23)$ \\
\hline
\end{tabular}

${ }^{a}$ Each child in the subset was observed eating school breakfast and school lunch (with both meals observed on the same day).

${ }^{b}$ Breakfast participation was the number of days on which a child participated in school breakfast during his or her fourth-grade school year.

${ }^{c}$ Lunch participation was the number of days on which a child participated in school lunch during his or her fourth-grade school year.

${ }^{d}$ Combined participation was the number of days on which a child participated in both school breakfast and school lunch during his or her fourth-grade school year.

the healthy weight, overweight, obese, and severely obese BMI categories, $48 \%, 50 \%, 53 \%$, and $63 \%$ had breakfast in the classroom, respectively.

Breakfast participation, lunch participation, and combined participation were not significant for analysis of BMI or BMI category (all p values > 0.602). Also, school year was not significant for analysis of BMI or BMI category (all $\mathrm{p}$ values $>0.082$ ).

\section{RQ2}

For analysis of BMI, average observed energy intake for breakfast was not significant $(\mathrm{p}=0.062$; coefficient $=$ 0.39). However, for analysis of BMI category, average observed energy intake for breakfast was significant $(\mathrm{p}=$ 0.040 ; odds ratio $=1.22$ ); for the healthy weight, overweight, obese, and severely obese BMI categories, average observed energy intake for breakfast was 248,261 , 302, and 281 kilocalories, respectively. Thus, a child was 1.22 times as likely to be in the next heavier BMI category for every increase of 100 kilocalories in observed energy intake for breakfast.

For analysis of BMI, average observed energy intake for lunch was significant $(\mathrm{p}<0.001$; coefficient $=0.62)$. Thus, for every increase of 100 kilocalories in observed energy intake for lunch, there was a $0.62 \mathrm{~kg} / \mathrm{m}^{2}$ increase in BMI. Also, for analysis of BMI category, average observed energy intake for lunch was significant $(\mathrm{p}<$ 0.001 ; odds ratio $=1.21$ ); for the healthy weight, overweight, obese, and severely obese BMI categories, average observed energy intake for lunch was 470, 514, 580, and 588 kilocalories, respectively. Thus, a child was 1.21 times as likely to be in the next heavier BMI category for every increase of 100 kilocalories in observed energy intake for lunch.

For analysis of BMI, breakfast location was significant $(\mathrm{p}=0.021$; coefficient for classroom $=1.15)$; average BMI was larger for children with breakfast in the classroom (21.90) than in the cafeteria (20.48). However, for analysis of BMI category, breakfast location was not significant $(\mathrm{p}=0.090$; odds ratio for classroom $=1.44)$.

Sex, age, and school year were not significant for analysis of BMI (all p values $>0.161$ ). Also, school year was not significant for analysis of BMI category (all $\mathrm{p}$ values $>0.065)$.

\section{RQ3}

For analysis of BMI, average observed energy intake for breakfast was significant $(\mathrm{p}=0.045$; coefficient $=0.42)$. Thus, for every increase of 100 kilocalories in observed energy intake for breakfast, there was a $0.42 \mathrm{~kg} / \mathrm{m}^{2}$ increase in BMI. Also, for analysis of BMI category, average observed energy intake for breakfast was 
significant $(\mathrm{p}=0.037$; odds ratio $=1.24)$; for the healthy weight, overweight, obese, and severely obese BMI categories, average observed energy intake for breakfast was 248, 261, 302, and 281 kilocalories, respectively. Thus, a child was 1.24 times as likely to be in the next heavier BMI category for every increase of 100 kilocalories in observed energy intake for breakfast.

For analysis of BMI, average observed energy intake for lunch was significant $(\mathrm{p}<0.001$; coefficient $=0.62$ ). Thus, for every increase of 100 kilocalories in observed energy intake for lunch, there was a $0.62 \mathrm{~kg} / \mathrm{m}^{2}$ increase in BMI. Also, for analysis of BMI category, average observed energy intake for lunch was significant $(\mathrm{p}<$ 0.001 ; odds ratio $=1.22$ ); for the healthy weight, overweight, obese, and severely obese BMI categories, average observed energy intake for lunch was $470,514,580$, and 588 kilocalories, respectively. Thus, a child was 1.22 times as likely to be in the next heavier BMI category for every increase of 100 kilocalories in observed energy intake for lunch.

For analysis of BMI, breakfast location was significant $(\mathrm{p}=0.012$; coefficient for classroom $=1.29)$; average BMI was larger for children with breakfast in the classroom (21.90) than in the cafeteria (20.48). Also, for analysis of BMI category, breakfast location was significant $(\mathrm{p}=0.041$; odds ratio for classroom $=1.52)$; for the healthy weight, overweight, obese, and severely obese BMI categories, $54 \%, 63 \%, 63 \%$, and $74 \%$ had breakfast in the classroom, respectively.

Breakfast participation, lunch participation, and combined participation were not significant for analysis of BMI or BMI category (all p values $>0.072$ ). Sex and age were not significant for analysis of BMI (both p values > $0.149)$. School year was not significant for analysis of BMI or BMI category (all $\mathrm{p}$ values $>0.108$ ).

\section{Results from post-hoc analyses}

A post-hoc two sample $t$-test of observed energy intake for breakfast by breakfast location showed that significantly more energy was observed eaten for breakfast in the classroom (276 kilocalories) than in the cafeteria (250 kilocalories; $\mathrm{p}=0.017$ ). However, a post-hoc two sample $t$-test of observed energy intake for lunch by breakfast location showed no significant difference $(\mathrm{p}=$ 0.875; 515 kilocalories in the classroom; 512 kilocalories in the cafeteria).

A post-hoc two sample $t$-test of observed energy intake for breakfast by sex showed that significantly more energy was observed eaten by boys (286 kilocalories) than girls (243 kilocalories; $\mathrm{p}<0.001)$. Likewise, a post-hoc two sample $t$-test of observed energy intake for lunch by sex showed that significantly more energy was observed eaten by boys ( 540 kilocalories) than girls (487 kilocalories; $\mathrm{p}=0.005$ ).

\section{Discussion}

Results from the current analyses showed that daily participation in school breakfast, school lunch, and both school meals combined was not significantly associated with BMI or BMI category (for RQ1 and for RQ3). Although these results agree with those of the Expert Panel convened in March, 2004 [9], the results concerning participation in school breakfast and BMI differ with results from the third School Nutrition Dietary Assessment Study [18] which showed a negative relationship between school breakfast participation and BMI percentile. For that study, children reported their usual weekly participation in school breakfast and in school lunch. However, the current analyses used daily SBP and NSLP participation obtained from electronic administrative records provided by the school district.

Breakfast location was significant for BMI for RQ1, RQ2, and RQ3, and for BMI category for RQ3. When breakfast location was considered in post-hoc analyses, significantly more energy was observed eaten for breakfast in the classroom; however, observed energy intake for lunch by breakfast location showed no significant difference.

The significant effects of sex and age on BMI found in RQ1 were absent in the other two RQs where either observed energy intake or both daily participation and observed energy intake were included in the models. When sex was considered in post-hoc analyses, significantly more energy was observed eaten for breakfast and for lunch by boys.

Observed energy intake at breakfast and observed energy intake at lunch were positively associated with BMI and BMI category for RQ2 and RQ3 with the exception of BMI for observed energy intake at breakfast for RQ2. Similar to results from the current analyses, results from a small study with fourth-grade children showed that observed energy intake at school meals was positively associated with children's BMI percentile [38]. For that study, each of 20 children (15 Black; half girls) of low-BMI percentile $\left(\geq 5^{\text {th }}\right.$ and $<50^{\text {th }}$ percentiles) and 20 children (15 black; half girls) of high-BMI percentile ( $\geq 85^{\text {th }}$ percentile) was observed eating two school meals (breakfast, lunch) on a school day. More kilocalories were observed eaten by children of high-BMI percentile than low-BMI percentile $(\mathrm{p}<0.02)$, but no significant difference was found in kilocalories reported eaten by children of high-BMI percentile and low-BMI percentile [38].

The current analyses utilized SBP and NSLP participation regardless of whether children received school meals for free, reduced price, or full price. This is appropriate because what is important is SBP and NSLP participation (i.e., obtaining the meal [s] at school) rather than meal price $[17,39]$. 
Limitations of the data analyzed include that the validation study that provided data for the current analyses was not designed to address the three RQs, nor was it designed to determine whether higher BMI causes children to eat more, whether eating more causes children to have higher BMIs, or both. No measures of physical activity or observed 24-hour intake were available, and weight/height measurements were available for only one time point per child. The sample included only fourthgrade, primarily Black children from one school district. The estimates of energy yielded by the use of standardized school meal portions may be somewhat imprecise, but the same process was used consistently for each observed child for each observed school meal irrespective of children's BMI or BMI category.

An important strength of the analyses in the current article is that participation in school meals was determined using electronic administrative records of daily participation obtained from the school district, rather than crude summary measures of parental- or selfreports of school meal participation (e.g., yes/no dichotomous reports for the year; or weekly summary measures of usual participation). Another strength is that direct observation of school meals was used to determine energy intake; thus, the use of parent's and/or children's reports of children's intake was avoided. An additional strength is that rigorous quality control measures were implemented for school meal observations as well as for weight and height measurements. A final strength is that for all children, weight and height were measured after breakfast, but before lunch.

\section{Conclusions}

The secondary analyses of the current article were a cost-efficient step to add new knowledge and inform the design of future controlled trials and/or cohort studies aimed at understanding pathways to obesity among children who participate in school meals. Longitudinal studies with weight/height measurements at the beginning and end of each school year during elementary school, along with children's daily participation in school meals during elementary school, could help resolve concerns about a relationship between participation in school meals and childhood obesity. School meal observations conducted during each year of elementary school, and other desirable data (such as physical activity), should be included if allowed by budgets.

Additional studies are needed to extend the current article's results which indicated positive relationships between children's BMI and observed energy intake at school meals, and between children's BMI and school breakfast in the classroom. For example, does the energy content of school breakfast differ by location (classroom; cafeteria)? Does the energy content of school meals differ by children's BMI whether offer-vs-serve foodservice is implemented? Results from such studies could provide important guidance for policy changes concerning school meals.

\section{List of abbreviations}

BMI: body mass index; SBP: School Breakfast Program; NSLP: National School Lunch Program; RQ: research question.

\section{Acknowledgements}

This research was supported by competitive grants R01HL074358 and R21HL088617 (with SDB as Principal Investigator for both grants) from the National Heart, Lung, and Blood Institute of the National Institutes of Health. The content of this article is solely the responsibility of the authors and does not necessarily represent the official views of the National Heart, Lung, and Blood Institute or the National Institutes of Health.

The authors appreciate the cooperation of children, faculty, and staff of elementary schools, and staff of Student Nutrition Services, of the Richland One School District (Columbia, SC, USA).

The authors appreciate the contribution to this work of Amy F. Joye, MS, RD, who was Project Director for R01HL074358 until she suffered severe brain damage due to a medical tragedy at age 36. The Amy Joye Memorial Research Award has been established through the American Dietetic Association Foundation to award nutrition research grants in Amy's memory.

\section{Author details}

${ }^{1}$ Institute for Families in Society, University of South Carolina, 1600 Hampton Street, Suite 507, Columbia, SC 29208 USA. ${ }^{2}$ Department of Epidemiology and Biostatistics, University of South Carolina, Columbia, SC 29208 USA.

\section{Authors' contributions}

SDB conceived the study, participated in the study's design and coordination, and drafted the manuscript. JWH performed the statistical analyses and helped to draft the manuscript. CHG participated in quality control and data coding, and helped to draft the manuscript. JAR was responsible for data management/programming and helped with statistical analyses. AJM and CMD participated in the recruitment of schools and participants, acquisition of data, quality control, data entry, and data coding. All authors read and approved the final manuscript.

\section{Authors' information}

SDB is a Research Professor in the Institute for Families in Society at the University of South Carolina in Columbia, South Carolina, USA; she is a Registered and Licensed Dietitian, and a Fellow of the American Dietetic Association. JWH is a Research Associate Professor in the Department of Epidemiology and Biostatistics, and Director of the Biostatistics Collaborative Unit at the University of South Carolina in Columbia, South Carolina, USA. CHG is a Research Dietitian in the Institute for Families in Society at the University of South Carolina in Columbia, South Carolina, USA; she is a Registered and Licensed Dietitian. JAR is a Research Associate in the Institute for Families in Society at the University of South Carolina in Columbia, South Carolina, USA. AJM is a Research Specialist II in the Institute for Families in Society at the University of South Carolina in Columbia, South Carolina, USA. CMD is a Research Dietitian in the Institute for Families in Society at the University of South Carolina in Columbia, South Carolina, USA; she is a Registered and Licensed Dietitian.

\section{Competing interests}

The authors declare that they have no competing interests.

Received: 30 November 2009 Accepted: 24 March 2010 Published: 24 March 2010

\section{References}

1. Hedley $A A$, Ogden $C L$, Johnson $C L$, Carroll MD, Curtin LR, Flegal KM: Prevalence of overweight and obesity among US children, adolescents, and adults, 1999-2002. JAMA 2004, 291:2847-2850. 
2. Ogden $C L$, Carroll MD, Curtin LR, McDowell MA, Tabak CJ, Flegal KM: Prevalence of overweight and obesity in the United States, 1999-2004. JAMA 2006, 295:1549-1555.

3. Wang $Y$, Lobstein $\mathrm{T}$ : Worldwide trends in childhood overweight and obesity. Int J Pediatr Obes 2006, 1:11-25.

4. Ebbeling CB, Pawlak DB, Ludwig DS: Childhood obesity: public-health crisis, common sense cure. Lancet 2002, 360:473-482.

5. The Food Assistance Landscape: FY 2008 Annual Report. [http://www.ers. usda.gov/Publications/EIB6-6/].

6. National School Lunch Program. [http://www.fns.usda.gov/cnd/lunch/ AboutLunch/NSLPFactSheet.pdf].

7. The National School Lunch Program: Background, Trends, and Issues. Economic Research Report No. EER-61. [http://www.ers.usda.gov/ Publications/ERR61/]

8. Story M, Kaphingst KM, Robinson-O'Brien R, Glanz K: Creating healthy food and eating environments: Policy and environmental approaches. Annu Rev Public Health 2008, 29:253-272.

9. Obesity, Poverty, and Participation in Food Assistance Programs, Report No. FSP-04-PO, Project Officer, S Cristofar. [http://www.fns.usda.gov/oane/ MENU/Published/NutritionEducation/Files/ObesityPoverty.pdf\#xml=http:// 65.216.150.153/texis/search/pdfhi.txt?query=FSP-04PO\&pr $=F N S \&$ order $=r \& c q=\& i d=4592 d 05717]$.

10. Nicklas TA, Baranowski T, Cullen KW, Berenson G: Eating patterns, dietary quality and obesity. J Am Coll Nutr 2001, 20:599-608.

11. Paige DM: The school feeding program: An underachiever. J Sch Health 1972, 42:392-395.

12. Lieberman HM, Hunt IF, Coulson AH, Clark VA, Swendseid ME, Ho L: Evaluation of a ghetto school breakfast program. J Am Diet Assoc 1976, 68:132-138.

13. Vermeersch J, Hanes S, Gale S: The National Evaluation of School Nutrition Programs: Program impact on anthropometric measures. Am J Clin Nutr 1984, 40:414-424.

14. Wolfe WS, Campbell CC, Frongillo EA Jr, Haas JD, Melnik TA: Overweight schoolchildren in New York State: Prevalence and characteristics. Am J Public Health 1994, 84:807-813.

15. Melnik TA, Rhoades SJ, Wales KR, Cowell C, Wolfe WS: Overweight school children in New York City: Prevalence estimates and characteristics. Int J Obes 1998, 22:7-13.

16. Jones SJ, Jahns L, Laraia BA, Haughton B: Lower risk of overweight in school-aged food insecure girls who participate in food assistance. Arch Pediatr Adolesc Med 2003, 157:780-784.

17. Hofferth SL, Curtin S: Poverty, food programs, and childhood obesity. J Policy Anal Manage 2005, 24:703-726.

18. Gleason P, Briefel R, Wilson A, Dodd AH, Mathematica Policy Research, Inc: School meal program participation and its association with dietary patterns and childhood obesity, Contractor and Cooperator Report Number 55. 2009 [http://hdl.handle.net/10113/35896].

19. Guinn CH, Baxter SD, Thompson WO, Frye FHA, Kopec CT: Which fourthgrade children participate in school breakfast and do their parents know it? J Nutr Educ Behav 2002, 34:159-165.

20. Eck LH, Klesges RC, Hanson CL: Recall of a child's intake from one meal: Are parents accurate? J Am Diet Assoc 1989, 89:784-789.

21. Emmons L, Hayes M: Accuracy of 24-hr. recalls of young children. J Am Diet Assoc 1973, 62:409-415.

22. Mack KA, Blair J, Presser S: Measuring and improving data quality in children's reports of dietary intake. Health Survey Research Methods Conference Proceedings. DHHS publication no. (PHS) 96-1013 Hyattsville, MD: US Department of Health and Human ServicesWarnecke RB 1996, 51-55.

23. Baranowski T, Islam N, Baranowski J, Cullen KW, Myres D, Marsh T, de Moor C: The Food Intake Recording Software System is valid among fourth-grade children. J Am Diet Assoc 2002, 102:380-385.

24. Baxter SD, Smith AF, Guinn CH, Thompson WO, Litaker MS, Baglio ML, Shaffer NM, Frye FHA: Interview format influences the accuracy of children's dietary recalls validated with observations. Nutr Res 2003, 23:1537-1546.

25. Lytle LA, Murray DM, Perry CL, Eldridge AL: Validating fourth-grade students' self-report of dietary intake: Results from the 5-A-Day Power Plus program. J Am Diet Assoc 1998, 98:570-572.

26. Warren JM, Henry CJK, Livingstone MBE, Lightowler HJ, Bradshaw SM, Perwaiz S: How well do children aged 5-7 years recall food eaten at school lunch? Pub Health Nutr 2003, 6:41-47.
27. Bernstein LS, McLaughlin JE, Crepinsek MK, Daft LM: Evaluation of the School Breakfast Program Pilot Project: Final Report. Nutrition Assistance Program Report Series, No. CN-04-SBP, Project Officer: Anita Singh. 2004 [http://www.fns.usda.gov/oane/MENU/published/CNP/FILES/SBPPFinal.pdf].

28. McLaughlin JE, Bernstein LS, Crepinsek MK, Daft LM, Murphy JM: Evaluation of the School Breakfast Program Pilot Project: Findings from the First Year of Implementation. Nutrition Assistance Program Report Series, No. CN-02-SBP, Project Officer: Anita Singh. 2002 [http://www.fns.usda.gov/ oane/menu/Published/CNP/FILES/BreakfastPilotYr1.pdf].

29. Baxter SD, Hardin JW, Guinn CH, Royer JA, Mackelprang AJ, Smith AF: Fourth-grade children's dietary recall accuracy is influenced by retention interval (target period and interview time). J Am Diet Assoc 2009, 109:846-856.

30. Road to SMI Success - A Guide for School Foodservice Directors. [http:// www.fns.usda.gov/tn/Resources/roadtosuccess.html].

31. Lohman TG, Roche AF, Martorell R: Anthropometric Standardization Reference Manual Champaign, IL: Human Kinetics Books 1988.

32. Accurately weighing \& measuring: Technique. [http://depts.washington. edu/growth/module5/text/intro.htm].

33. BMI Percentile Calculator for Child and Teen: English Version. [http:// apps.nccd.cdc.gov/dnpabmi/Calculator.aspx].

34. Kuczmarski RJ, Ogden CL, Guo SS, Grummer-Strawn LM, Flegal KM, Mei Z, Wei R, Curtin LR, Roche AF, Johnson CL: 2000 CDC Growth Charts for the United States: Methods and development. Vital Health Stat National Center for Health Statistics 2002, 11(246).

35. Barlow SE, the Expert Committee: Expert Committee Recommendations Regarding the Prevention, Assessment, and Treatment of Child and Adolescent Overweight and Obesity: Summary Report. Pediatrics 2007, 120:S163-S192.

36. Baglio ML, Baxter SD, Guinn CH, Thompson WO, Shaffer NM, Frye FHA: Assessment of interobserver reliability in nutrition studies that use direct observation of school meals. J Am Diet Assoc 2004, 104:1385-1393.

37. Hardin JW: The Sandwich Estimate of Variance. Maximum Likelihood Estimation of Misspecified Models: Twenty Years Later, Advances in Econometrics New York: ElsevierFomby T, Carter Hill R 2003, 305-325.

38. Baxter SD, Smith AF, Litaker MS, Guinn CH, Nichols MN, Miller PH, Kipp K: Body mass index, sex, interview protocol, and children's accuracy for reporting kilocalories observed eaten at school meals. J Am Diet Assoc 2006, 106:1656-1662

39. Gleason PM, Suitor CW: Eating at school: How the National School Lunch Program affects children's diets. Am J Agric Econ 2003, 85(4):1047-1061.

\section{doi:10.1186/1479-5868-7-24}

Cite this article as: Baxter et al:: Children's body mass index,

participation in school meals, and observed energy intake at school meals. International Journal of Behavioral Nutrition and Physical Activity 2010 7:24.

\section{Submit your next manuscript to BioMed Central and take full advantage of:}

- Convenient online submission

- Thorough peer review

- No space constraints or color figure charges

- Immediate publication on acceptance

- Inclusion in PubMed, CAS, Scopus and Google Scholar

- Research which is freely available for redistribution 